\title{
Mechanical Analysis of an SM-2 BLK IV Restrained Firing Within a Concentric Canister Launcher Test Unit
}

T.C. Kennedy, M.E. Kassner, T. Puttapitukporn and R.S. Rosen

\section{March 1, 1999}

U.S. Department of Energy

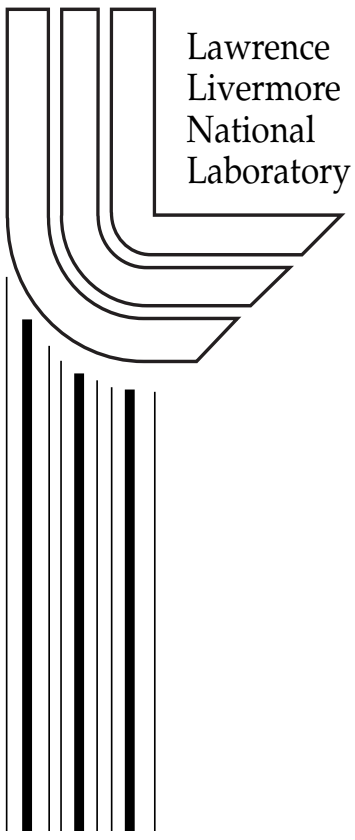




\section{DISCLAIMER}

This document was prepared as an account of work sponsored by an agency of the United States Government. Neither the United States Government nor the University of California nor any of their employees, makes any warranty, express or implied, or assumes any legal liability or responsibility for the accuracy, completeness, or usefulness of any information, apparatus, product, or process disclosed, or represents that its use would not infringe privately owned rights. Reference herein to any specific commercial product, process, or service by trade name, trademark, manufacturer, or otherwise, does not necessarily constitute or imply its endorsement, recommendation, or favoring by the United States Government or the University of California. The views and opinions of authors expressed herein do not necessarily state or reflect those of the United States Government or the University of California, and shall not be used for advertising or product endorsement purposes.

Work performed under the auspices of the U. S. Department of Energy by the University of California Lawrence Livermore National Laboratory under Contract W-7405-Eng-48.

This report has been reproduced directly from the best available copy.

Available to DOE and DOE contractors from the

Office of Scientific and Technical Information

P.O. Box 62, Oak Ridge, TN 37831

Prices available from (423) 576-8401

http://apollo.osti.gov/bridge/

Available to the public from the National Technical Information Service

U.S. Department of Commerce 5285 Port Royal Rd., Springfield, VA 22161 http://www.ntis.gov/

OR

Lawrence Livermore National Laboratory Technical Information Department's Digital Library http://www.llnl.gov/tid/Library.html 


\title{
MECHANICAL ANALYSIS OF AN SM-2 BLK IV RESTRAINED FIRING WITHIN A CONCENTRIC CANISTER LAUNCHER TEST UNIT
}

\author{
by \\ T. C. Kennedy \\ M. E. Kassner \\ T. Puttapitukporn \\ Department of Mechanical Engineering \\ Oregon State University \\ Corvallis, Oregon 97331 \\ and \\ R. S. Rosen \\ Lawrence Livermore National Laboratory \\ Livermore, California 94551
}

March 1999

Prepared for NSWCDD Weapons Systems Department

NSWCDD/TN-99/18 


\section{FOREWORD}

This report describes the results of a computer simulation of the structural response of a Concentric Canister Launcher (CCL) during a restrained firing, one in which an SM-2 Blk IV missile would fail to exit the canister. The work was carried out in support of Naval Surface Warfare Center, Dahlgren Division (NSWCDD) as part of one author's (Rosen's) Naval Reserve assignment as Commanding Officer of the Naval Reserve Surface Warfare Center Detachment 106, Washington, D.C. T. C. Kennedy is a Professor of Mechanical Engineering and M. E. Kassner is the Northwest Aluminum Professor of Mechanical Engineering and Director of the Graduate Program in Materials Science at Oregon State University, Corvallis, Oregon. T. Puttapitukporn is a graduate student at Oregon State University. R. S. Rosen is a member of Lawrence Livermore National Laboratory, Livermore, California, and is currently assigned to the Washington Operations Office in Germantown, Maryland.

J. J. Yagla of the Combat Systems Safety and Engineering Division of the Weapons System Department has reviewed this report.

Approved by:

ROBERT L. STIEGLER, Head

Weapons Systems Safety and

Engineering Division 


\section{INTRODUCTION}

The Office of Naval Research (ONR) and PMS512 have undertaken a program to develop a new Vertical Launching System (VLS) for future generation ships, such as the DD-21

Destroyer. The Naval Sea Systems Command Combat Weapons Program (NAVSEA 05K) and Naval Surface Warfare Center Dahlgren Division (NSWCDD) are working jointly with industry and universities to develop one such launcher design, the Concentric Canister Launcher (CCL).

The basic CCL design consists of a tube made of two concentric cylinders; one end is open, the other is sealed with a hemispherical end cap. During firing, the missile exhaust gas is turned 180 degrees by the hemispherical end cap and flows through the annular space between inner and outer cylinders. Depending on the missile utilized and the particular service environment of the CCL, maximum temperatures within the cylinder material have been calculated to exceed $2000^{\circ} \mathrm{F}$. In an earlier study [1], the authors determined the high temperature mechanical properties of several candidate alloys being considered for fabrication of the CCL. This study [1] found that, of these candidate materials, titanium alloys exhibit higher yield stresses than that of 316L stainless steel at temperatures up to about $1000^{\circ} \mathrm{F}$; above $1500^{\circ} \mathrm{F}$, the yield stress of $316 \mathrm{~L}$ stainless steel is comparable to those of the titanium alloys. The 316L stainless steel was found to strain harden (increase its flow stress with increasing strain) at temperatures up to about $1800^{\circ} \mathrm{F}$. The ability of the 316L stainless steel to strain harden at high temperatures may provide an added margin of safety for engineering design of the CCL.

The objective of the current study was to perform a computer simulation of the structural response of a CCL during a restrained firing, one in which a SM-2 Blk IV missile would fail to exit the canister. A finite element model of the inner cylinder, outer cylinder, end rings (mounting brackets), and lateral restraints in the uptake was constructed. An elastic-plastic, quasi-static analysis was performed using temperature dependent material properties of $316 \mathrm{~L}$ stainless steel. Modeling details are described in the CCL Structure section of this report.

\section{EXPERIMENTAL PROCEDURE}

\section{STRUCTURE}

A cross section of the CCL, as configured for a SM-2 Blk IV missile, is shown in Fig. 1a. It consists of an outer cylinder with a diameter of 34 in., four arcs making up a partial inner cylinder with an inner diameter of 22 in., four channel sections which serve as fin guides connecting the inner and outer cylinders, and four internal web sections running between the centers of the inner and outer cylinders in the uptake region. These radial web sections have been added along the center of each of the channels as additional support to reduce the potential for buckling of the inner cylinder wall during restrained firing [2]. The canister section is $261.6 \mathrm{in}$. long, and all walls are $0.375 \mathrm{in}$. thick except for the internal webs that are $0.090 \mathrm{in}$. thick. At the bottom is a supporting ring (which is used in the CCL test unit configuration to attach the 
hemispherical end cap) with a diameter of $38.245 \mathrm{in}$. and a length of $1.5 \mathrm{in}$. along the axis of the CCL. A second ring, with a diameter of 35.99 in. and a length of 2 in. along the axis of the CCL, is located at the top of the tube and serves as a mounting bracket for this test unit. A full view of the CCL test unit is shown in Fig. 1b (the hemispherical end cap was not included in the modeling of the CCL).

The material for all components of the CCL is $316 \mathrm{~L}$ stainless steel. The test unit configuration, as taken from NAVSEA Drawing No. 7250992, consists of a rocket booster motor located near the bottom end of the CCL, and a set of four dorsal fins located about midway along the CCL. The rocket motor casing fits inside the inner cylinder and was modeled as a rigid cylinder with an outer diameter of 21.045 in. and a length of 56.46 in. starting at a distance of 3.3 in. above the bottom ring. The restraints provided by the missile fins were modeled as line restraints acting at the center of the channel sections over an axial length of $62.2 \mathrm{in}$. beginning at a distance of $117.9 \mathrm{in}$. from the bottom ring. A side view of the CCL configuration as modeled in this analysis is shown in Fig. 1c.

\section{LOADS}

The load on the canister results from high temperature gas flowing through the uptake regions between the inner and outer cylinders. The gas applies pressure to the contact surfaces and causes a temperature rise in the metal. For the case of the SM-2 Blk IV booster motor, the duration of a restrained firing would be approximately 6 seconds. The pressure and temperature distributions as functions of distance along the cylinder axis (and, for the temperature distribution, also as functions of distance into the wall thickness) were developed using computational fluid dynamics (CFD) provided by the Naval Surface Warfare Center [3]. The maximum pressure distribution (corresponding to 6 seconds of restrained firing) from the CFD analysis is shown in Fig. 2. For computational purposes, this distribution was replaced by a linear one given by

$$
\mathrm{p}=54.3-0.0854 \mathrm{z}
$$

where $\mathrm{p}$ is the pressure in psig and $\mathrm{z}$ is the distance in inches along the length of the canister, referenced from $\mathrm{z}=0$ at the bottom end. This distribution was based on a linear fit to the highest pressures along the canister and therefore slightly over-estimates (by less than 3\%) the pressure along part of the length of the canister. Temperature distributions provided by the Naval Surface Warfare Center [3] accounted for the variation of temperature as a function of distance into the wall thickness, and were calculated at several points along the length of the axis $(6,38,72,150$, and 250 in.). These plots are shown in Appendix A, and include temperature distributions for times up to 6 seconds firing of the booster motor, where the maximum temperatures occur. It can be seen that, after 6 seconds of firing, the $316 \mathrm{~L}$ stainless steel wall begins to melt (the solidus is $2500^{\circ} \mathrm{F}$; the liquidus is $2550^{\circ} \mathrm{F}$ ) within 0.020 and 0.015 inches of the initial inner surface at 6 and $38 \mathrm{in}$. along the CCL, respectively. Therefore, the inner surfaces of the CCL from $\mathrm{z}=0$ to $\mathrm{z}=38 \mathrm{in}$. were reduced in thickness by $0.020 \mathrm{in}$. in the model to account for erosion from melting. The temperatures on the inner surface (distance into the wall equal to $0 \mathrm{in}$.) and those of the outer surface (distance into the wall equal to 0.375 in.), were used from these plots to develop the following functions for the temperature profiles 


$$
\begin{aligned}
& \mathrm{T}_{\mathrm{i}}=802+11660 \mathrm{z}^{-0.5295} \\
& \mathrm{~T}_{\mathrm{o}}=283+25187 \mathrm{z}^{-1.015}
\end{aligned}
$$

where $T_{i}$ and $T_{o}$ are in degrees $F$ for the inner and outer wall surfaces, respectively, and $z$ is in inches. A plot of the temperature distribution, as used in this analysis, is shown in Fig. 3. This distribution was based on a linear fit from $T_{i}$ to $T_{o}$ and therefore slightly over-estimates the distribution shown in Appendix A. Because the CFD modeling did not include the web section [3], this same temperature distribution and reduction in thickness from melting were also utilized for the web sections to analyze the deformation of the CCL. The temperature distribution for the thinner web material ( 0.090 in.) is expected to be higher than that of the thicker wall material ( 0.375 in.) and, therefore, results of the analysis incorporating web sections should be assumed to be nonconservative.

\section{MATERIAL PROPERTIES}

All components of the CCL that were analyzed were composed of $316 \mathrm{~L}$ stainless steel. Mechanical properties were needed in the temperature range from $70^{\circ} \mathrm{F}$ to $2500^{\circ} \mathrm{F}$. Young's modulus E was obtained from Piatti and Schiller [4] and Brown, Mindlin, and Ho [5]. A leastsquares fit of the data was made to the cubic polynomial

$$
\mathrm{E}=\left(28.8-0.0072 \mathrm{~T}+1.58 \times 10^{-6} \mathrm{~T}^{2}-9.52 \times 10^{-10} \mathrm{~T}^{3}\right) \times 10^{6}
$$

where $\mathrm{E}$ is in psi and T is temperature in degrees F. Poisson's ratio was found to be relatively insensitive to temperature and was taken as a constant value of 0.3 . The coefficient of thermal expansion $\alpha$ was obtained from [4] and was fit to the cubic polynomial

$$
\alpha=\left(8.17+0.00322 \mathrm{~T}-1.52 \times 10^{-6} \mathrm{~T}^{2}+3.06 \times 10^{-10} \mathrm{~T}^{3}\right) \times 10^{-6}
$$

where $\mathrm{T}$ is in degrees $\mathrm{F}$. Plasticity properties were obtained from stress-strain curves in Kashyap, McTaggart, and Tangri [6] for temperatures between $70^{\circ} \mathrm{F}$ and $1652^{\circ} \mathrm{F}$. Plasticity properties at $2000^{\circ} \mathrm{F}$ and $2500^{\circ} \mathrm{F}$ were obtained by extrapolating the data from [6] using the relation

$$
\mathrm{d} \varepsilon / \mathrm{dt}=\operatorname{Aexp}(-\mathrm{Q} / \mathrm{RT})(\sigma / \mathrm{E})^{\mathrm{n}}
$$

where $\mathrm{d} \varepsilon / \mathrm{dt}$ is the strain rate, $\mathrm{Q}$ is the activation energy for plastic flow, $\sigma$ is the flow stress, $\mathrm{n}$ is the stress exponent, $\mathrm{R}$ is the gas constant $(8.314 \mathrm{~J} / \mathrm{moleK}), \mathrm{E}$ is Young's modulus at temperature $\mathrm{T}$ in degrees $\mathrm{R}$, and $\mathrm{A}$ is a constant. It can be assumed that negligible strain hardening, corresponding to ideal elastic-plastic stress behavior, occurs at temperatures of $2000^{\circ} \mathrm{F}(1366 \mathrm{~K})$ and higher [1]. Therefore, the flow stresses $\left(\sigma_{2000,2500}\right)$ at $2000^{\circ} \mathrm{F}\left(\mathrm{T}_{2000}\right)$ and $2500^{\circ} \mathrm{F}\left(\mathrm{T}_{2500}\right)$ were obtained at a strain rate of $\mathrm{d} \varepsilon / \mathrm{dt}=10^{-3} / \mathrm{s}$ from [6] using the relation

$$
\sigma_{2000}=\sigma_{1}\left(\mathrm{E}_{2000} / \mathrm{E}_{1}\right) \exp \left[(\mathrm{Q} / \mathrm{R})\left(1 / \mathrm{T}_{2000}-1 / \mathrm{T}_{1}\right)\right]^{1 / \mathrm{n}}
$$


where $\sigma_{1}$ is the flow stress from [6] at $\mathrm{T}_{1}=1652^{\circ} \mathrm{F}(1173 \mathrm{~K}), \mathrm{Q}=320,000 \mathrm{~J} / \mathrm{mole}$ and $\mathrm{n}=5$ from [7]. The stress-strain curves used in the analysis are shown in Fig. 4.

\section{FINITE ELEMENT MODEL}

A finite element model was constructed using the ANSYS program [8]. A four-node, large strain, quadrilateral shell element was used for all components. A one-eighth symmetry model of the CCL was constructed as shown in Fig. 5. Temperatures and pressures were applied to the surfaces based on the distributions described in the Loads and Materials Properties sections of this report. The shell element assumes a linear variation in temperature through the thickness of the shell. This tends to over-estimate the temperature in the metal as noted in the Loads section. An elastic-plastic, quasi-static analysis including large deflection and finite strain effects was performed.

Three load cases were considered in this analysis. The first includes the restraint effects of both the rocket motor casing and the missile fins, and was evaluated both with and without the four internal web sections. The second includes the restraint effect of the rocket motor casing but not the missile fins, and was evaluated without the four internal web sections. The third includes neither the restraint effects of the rocket motor casing nor the missile fins, and was evaluated without the four internal web sections.

\section{RESULTS AND DISCUSSION}

\section{LOAD CASE 1}

The results for load case 1 are shown in Figs. 6 and 7 with and without the web sections present. Figs. $6 \mathrm{a}$ and $6 \mathrm{~b}$ show the deformed cross-section shape at the axial position where the deformation is largest with and without the web sections, respectively. Figs. 7a and $7 \mathrm{~b}$ show the radial displacement at the center of the inner and outer cylinders as a function of axial position with and without the web sections, respectively. The horizontal portion of the curve for the inner cylinder in the range $\mathrm{z}=3-60$ in. indicates that the inner cylinder has made contact with the rocket motor casing (corresponding to 0.5 in. deflection). For the case with web sections (Figs. 6a and $7 \mathrm{a}$ ), the inner wall deflection does not exceed $0.5 \mathrm{in}$. even beyond the rocket motor casing, and the outer wall deflection is limited to about 0.25 in. along the initial 40 in. of the CCL axis. For the case without web sections (Figs. $6 b$ and $7 b$ ), the inner wall deflection reaches a maximum of nearly $2.5 \mathrm{in}$. beyond the rocket motor casing, and the outer wall deflection is a maximum of about 0.75 in. at the same location along the CCL axis $(z=80-90$ in. $)$. The reduced displacement in the range $\mathrm{z}=120-180 \mathrm{in}$. indicates the restraint effect of the missile fins. Comparing the two curves, it is evident that the deformation of the inner and outer cylinders is coupled.

For the CCL without web sections, the maximum equivalent plastic strain in the structure occurs at the center of the inner cylinder and is 4.8 percent. For the structure with web sections, 
the maximum equivalent plastic strain occurs in the web and is 16.2 percent. The effect of the web sections is to produce a significantly reduced deflection in the inner and outer cylinders by carrying a fairly substantial amount of the load (as evidenced by the 16.2 percent strain). The ability of the web to carry this load is predicated on strain hardening of the 316 L stainless steel, which occurs at temperatures below about $1800^{\circ} \mathrm{F}$ (see Fig. 4 and reference [1]). However, the deformation of the CCL modeled with the web sections is believed to be nonconservative due to the assumed web temperature distribution and reduction in thickness from melting as discussed in the Loads section. Hence load cases 2 and 3 were only analyzed without the web sections.

\section{LOAD CASE 2}

The results for load case 2 (without missile fins or webs present) are given in Fig. 8, which shows the radial displacement at the center of the inner and outer cylinders as a function of axial position. The results in this figure are similar to that in Fig. 7b but without the missile fin restraint effect. The maximum deflections are nearly identical to the case with the missile fins, although the fins do provide a small amount of restraint as shown by the slightly greater displacement of the inner cylinder in the range $\mathrm{z}=120$-180 in. The maximum equivalent plastic strain in the structure occurs at the center of the inner cylinder and is 5.1 percent (compared with 4.8 percent with the fins).

\section{LOAD CASE 3}

The results for load case 3 (without rocket motor casing, missile fins, or webs present) are shown in Fig. 9, which again shows the radial displacement at the center of the inner and outer cylinders as a function of axial position. The displacements are significantly larger here than in the previous two load cases because of the absence of the restraint effects of the rocket motor casing (principally) and the missile fins. The maximum equivalent plastic strain in the structure occurs at the center of the inner cylinder and is 7.7 percent (compared with 5.1 percent with the motor casing and 4.8 percent with the motor casing and fins). This load case, of course, would never exist without the rocket motor casing, but it does serve to illustrate the beneficial effect of the restraint provided by the motor casing along the portion of the CCL where it is most needed (at the highest temperature and pressure region).

\section{CONSERVATISM OF ANALYSIS}

From the stress-strain curves (Fig. 4) it is evident that the CCL wall material should be sufficiently ductile to withstand this level of strain (less than 8 percent) without fracturing. For example, at $1472^{\circ} \mathrm{F}$, mill-annealed 316 stainless steel has a typical elongation of 75 percent, with a 2 -sigma minimum value of about 65 percent [9]. The minimum ductility for 316 stainless steel occurs at about $750^{\circ} \mathrm{F}$, with a typical elongation of about 40 percent, and a 2-sigma minimum value of about 30 percent [9].

To determine the sensitivity of the structural response to uncertainties in the internal 
pressure, load case 1 (without webs present) was reanalyzed with the pressure described by eq. (1) increased by a factor of three (163 psi maximum pressure). The displacements for this case are shown in Fig. 10. Comparing this with Fig. 7b, we observe that the maximum displacement has increased by only about 50 percent ( $3.5 \mathrm{in}$. compared with $2.5 \mathrm{in}$. for the normal pressure case). The reason for this relatively small increase is that, as the inner and outer cylinders deform, they tend to carry more of the load in hoop tension rather than bending; and this is a more efficient mode for carrying the pressure. The maximum equivalent strain for this case was 8.9 percent, which is well within the ductility limit for the material.

Conservatism used in the analysis of the CCL test unit included slightly overestimating (1) pressure distribution (linear fit to end points of concave upward curve), (2) erosion of wall material along initial 38 inches of the CCL axis (0.020 in. rather than linear fit to 0.020 at $\mathrm{z}=0$ and 0.015 at $\mathrm{z}=38$ in.), and (3) temperature distribution through the CCL wall (linear fit to end points of concave upward curves).

\section{SUMMARY}

A computer simulation of the structural response of a CCL test unit during an SM-2 Blk IV restrained firing was performed. A finite element model of the inner cylinder, outer cylinder, end rings (mounting brackets), and lateral restraints in the uptake was constructed. An elasticplastic, quasi-static analysis was performed using temperature dependent material properties of 316L stainless steel. Deflections of the inner and outer cylinder walls occur from loads on the canister due to high temperature gas flowing through the uptake regions. Our modeling results showed that the CCL wall material should be sufficiently ductile to withstand this level of strain without fracturing, even without the four internal web sections running between the centers of the inner and outer cylinders in the uptake region. However, without the web sections, deformation of the inner cylinder of the CCL between the missile's dorsal fins and the booster rocket motor casing would prevent the missile from being easily extracted after restrained firing. Additionally, deformation of the outer cylinder may prevent the CCL from being easily extracted from a ship weapons module after restrained firing. If these are important considerations, then the CFD modeling should be reanalyzed with the web sections to determine more accurate temperature distributions for the web material, and the results can then be used to reanalyze deformation of the CCL with the web sections present. 


\section{REFERENCES}

1. Rosen, R. S., Lowry, R. W., and Kassner, M. E., "High Temperature Properties of Alloys Being Considered for Design of a Concentric Canister Launcher." Naval Surface Warfare Center, Dahlgren Division, Dahlgren, VA 22482, NSWCDD/TR-98/72, June 1998.

2. Powers, J. W. and Settle, R. H., "Mechanical Analysis Supporting the Design of a HeavyWalled Tomahawk Concentric Canister Launcher." Naval Surface Warfare Center, Dahlgren Division, Dahlgren, VA 22482, NSWCDD/TR-96/227, May 1997, pp. 12-15.

3. Informal communication with L. Anderson, Jr., Naval Surface Warfare Center, Dahlgren Division/G72, October 1998.

4. Piatti, G. and Schiller, P., "Thermal and Mechanical Properties of the Cr-Mn-(Ni-Free) Austenitic Steels for Fusion Reactor Applications," Journal of Nuclear Materials, Vol.141143, 1986, pp. 417-426.

5. Brown, W.F., Mindlin, H., and Ho, C. Y., Aerospace Structural Metals Handbook, Purdue University, 1997.

6. Kashyap, B. P. McTaggart, K., and Tangri, K., "Study on the Substructure Evolution and Flow Behavior in Type 316L Stainless Steel over the Temperature Range 21-900C,"

Philosophical Magazine A, Vol. 57, 1988, pp. 97-114.

7. Klundt, R. H., Walser, B., Yoshio, M., Schmidt, C., Luthy, H., Miller, A., and Sherby, O. D., "Subgrain Refinement Strengthening in Stainless Steel Alloys," Dept. of Materials Science and Engineering, Stanford University, EY-76-S-03-0326-PA, 1980, pp.68-86.

8. ANSYS Engineering Analysis System - Theoretical Manual, ANSYS Inc., Houston, PA, 1994.

9. Brinkman, C. R., Sikka, V. K., and King, R. T., Nuclear Technology Vol. 33, 1977, pp. 7695 . 


\section{List of Figures}

Fig. 1 CCL test unit shown in (a) cross section, (b) full view, and (c) side view with rocket booster case and missile dorsal fins

Fig. 2. Pressure distribution along the axis of the CCL

Fig. 3. Temperature distribution along the axis of the cylinder

Fig. 4. Stress-strain curves for 316L stainless steel at various temperatures

Fig. 5. One-eighth symmetry finite element model of the CCL

Fig. 6. Deformed cross-section shape at the axial position of maximum deformation: undeformed structure (dashed lines); deformed structure (solid lines) (a) with webs and (b) without webs present

Fig. 7. Radial displacement at the center of the inner and outer cylinders as a function of axial position for load case 1 (a) with webs and (b) without webs present

Fig. 8. Radial displacement at the center of the inner and outer cylinders as a function of axial position for load case 2 (without missile fins or webs present)

Fig. 9. Radial displacement at the center of the inner and outer cylinders as a function of axial position for load case 3 (without rocket motor casing, missile fins, or webs present)

Fig 10. Radial displacement at the center of the inner and outer cylinders as a function of axial position for load case 1 (without webs present) subjected to over-pressurization

A-1. CCL wall temperature as a function of time, 6 inches from the base of the cylinder

A-2. CCL wall temperature as a function of time, 38 inches from the base of the cylinder

A-3. CCL wall temperature as a function of time, 72 inches from the base of the cylinder

A-4. CCL wall temperature as a function of time, 150 inches from the base of the cylinder

A-5. CCL wall temperature as a function of time, 250 inches from the base of the cylinder 


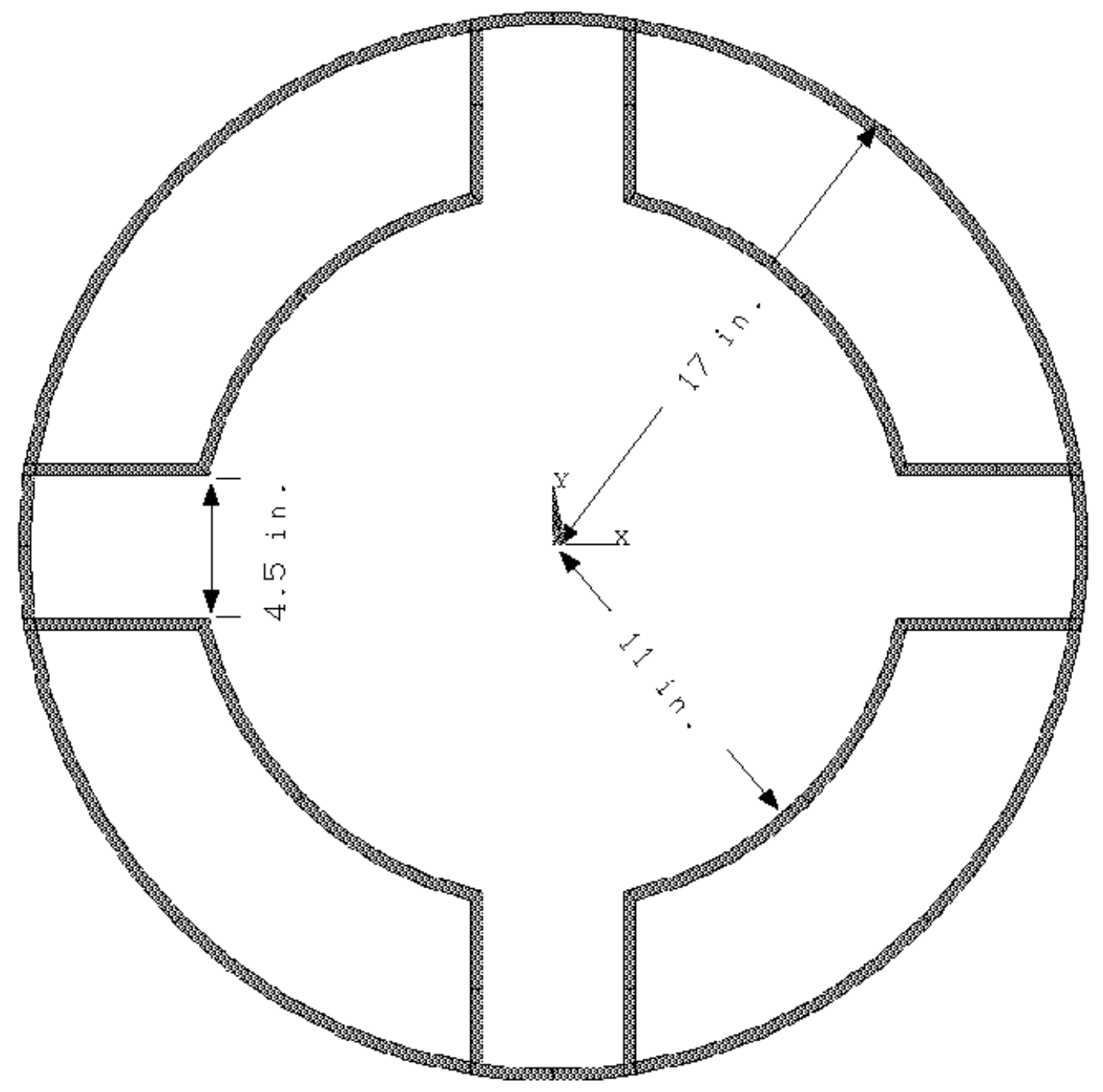

Figure 1a. CCL test unit shown in cross section 


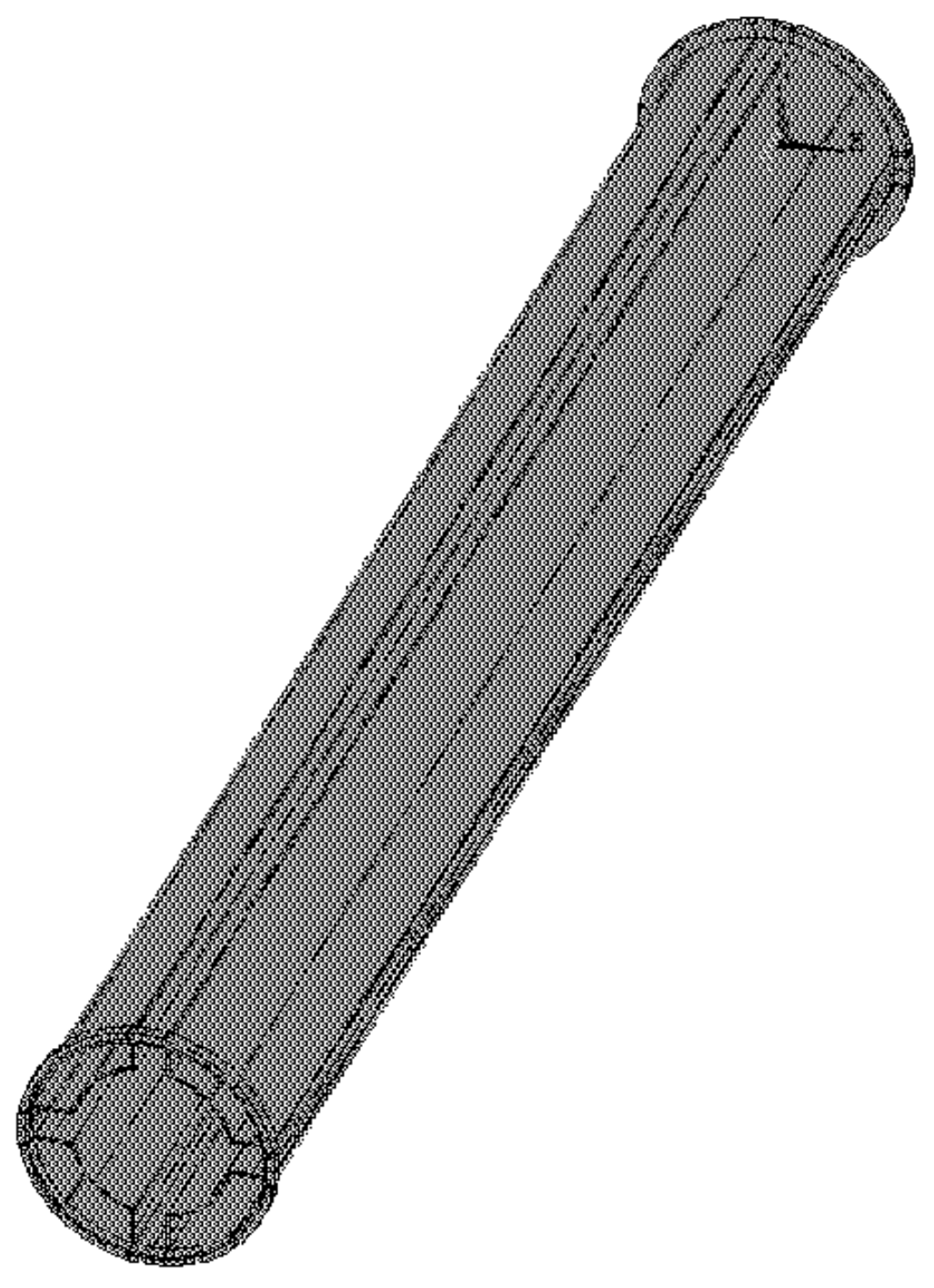

Figure 1b. CCL test unit shown in full view 


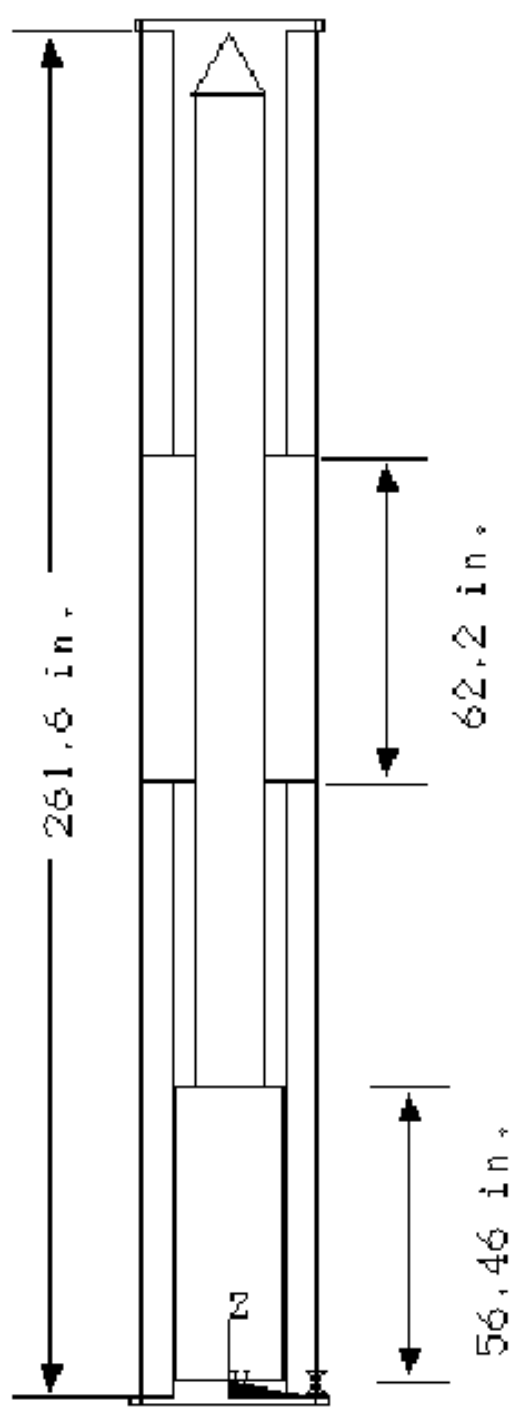

Figure 1c. CCL test unit shown in side view with rocket booster case and missile dorsal fins 


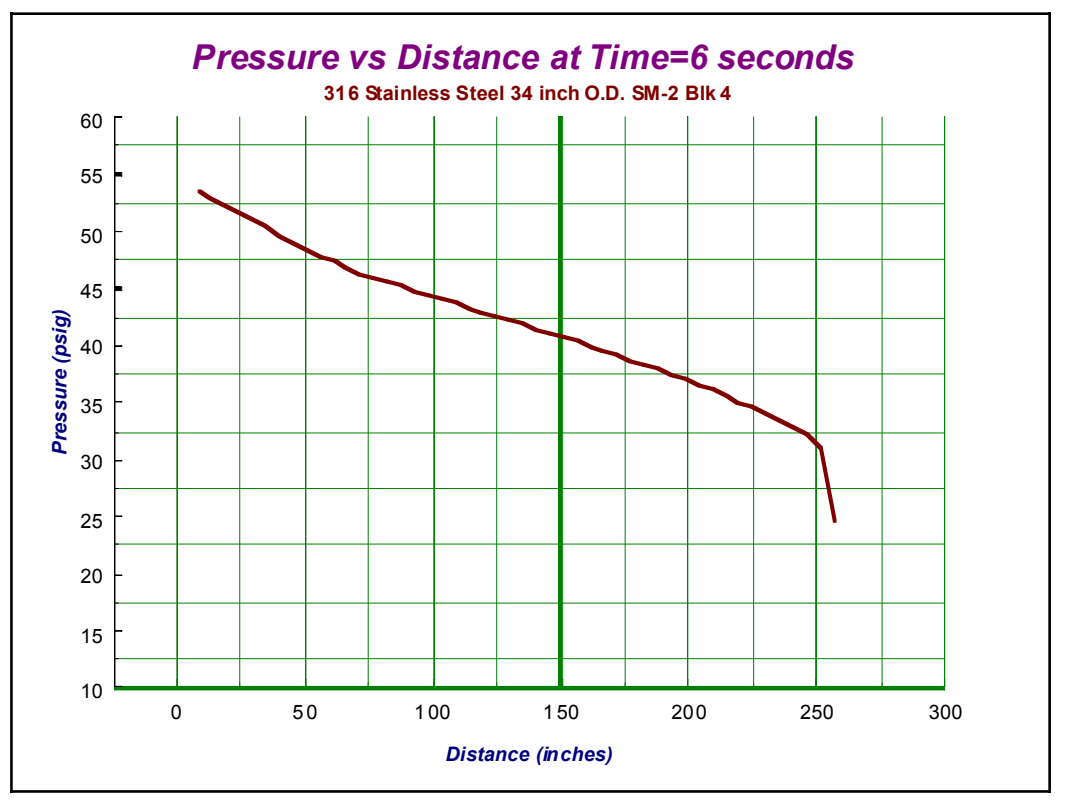

Figure 2. Pressure distribution along the axis of the CCL 


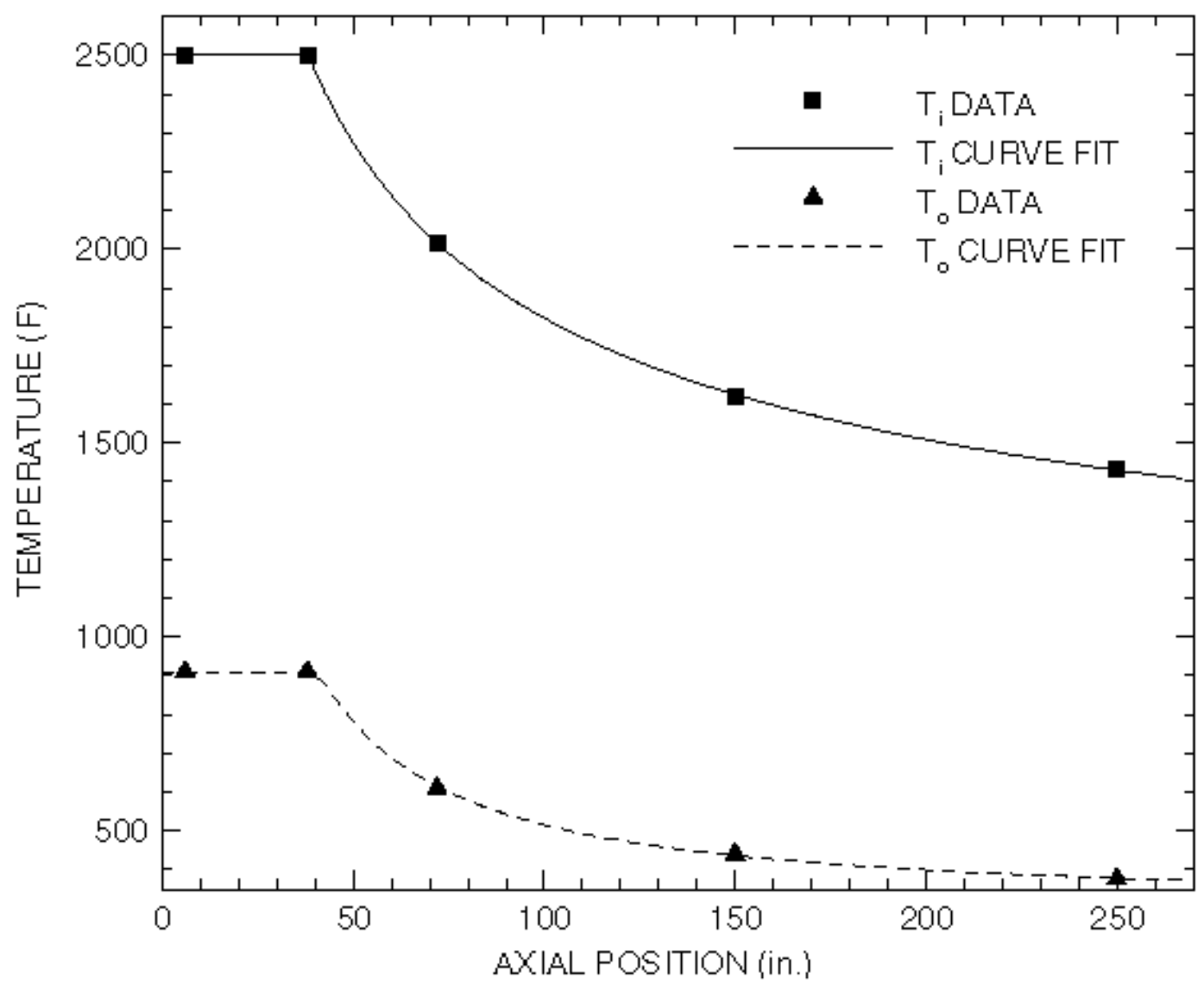

Figure 3. Temperature distribution along the axis of the cylinder 


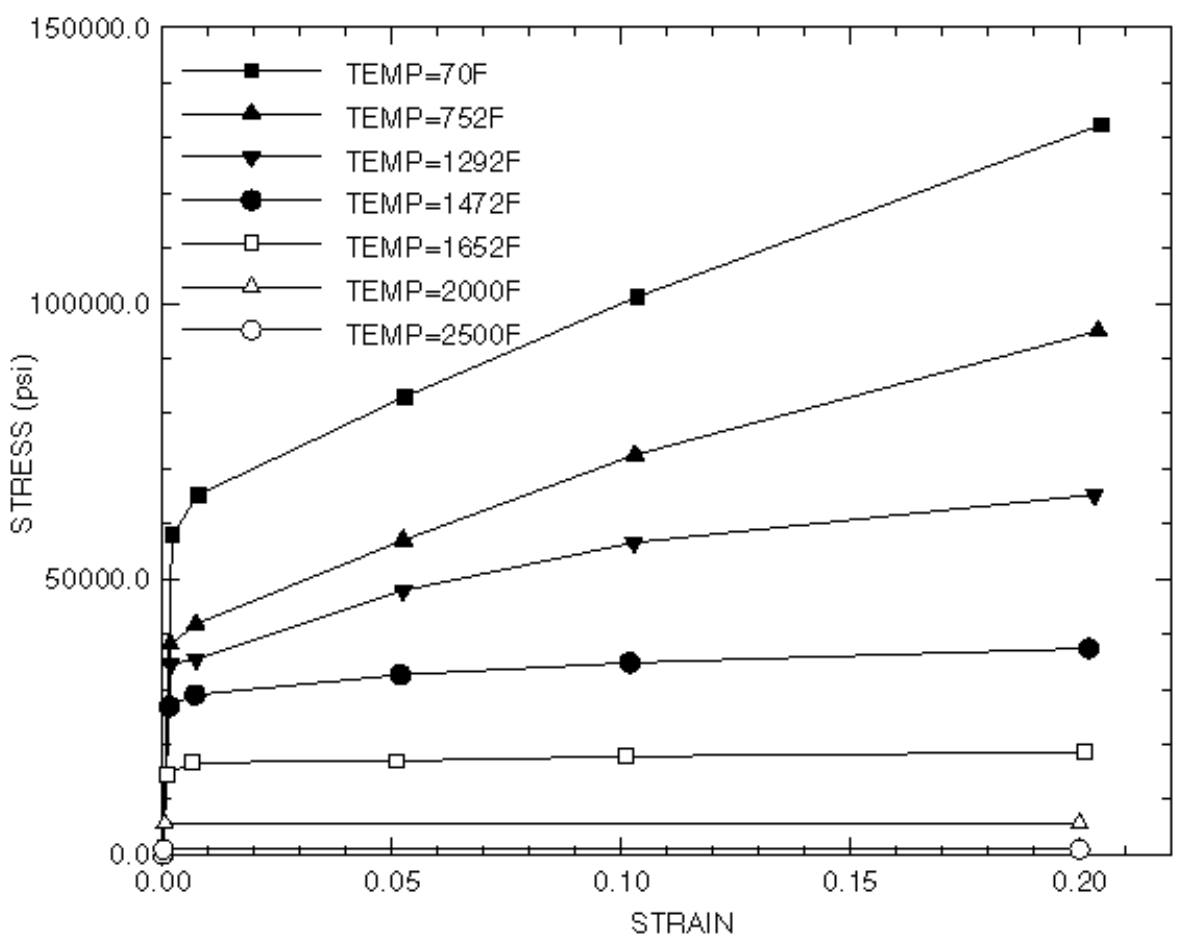

Figure 4. Stress-strain curves for 316L stainless steel at various temperatures 


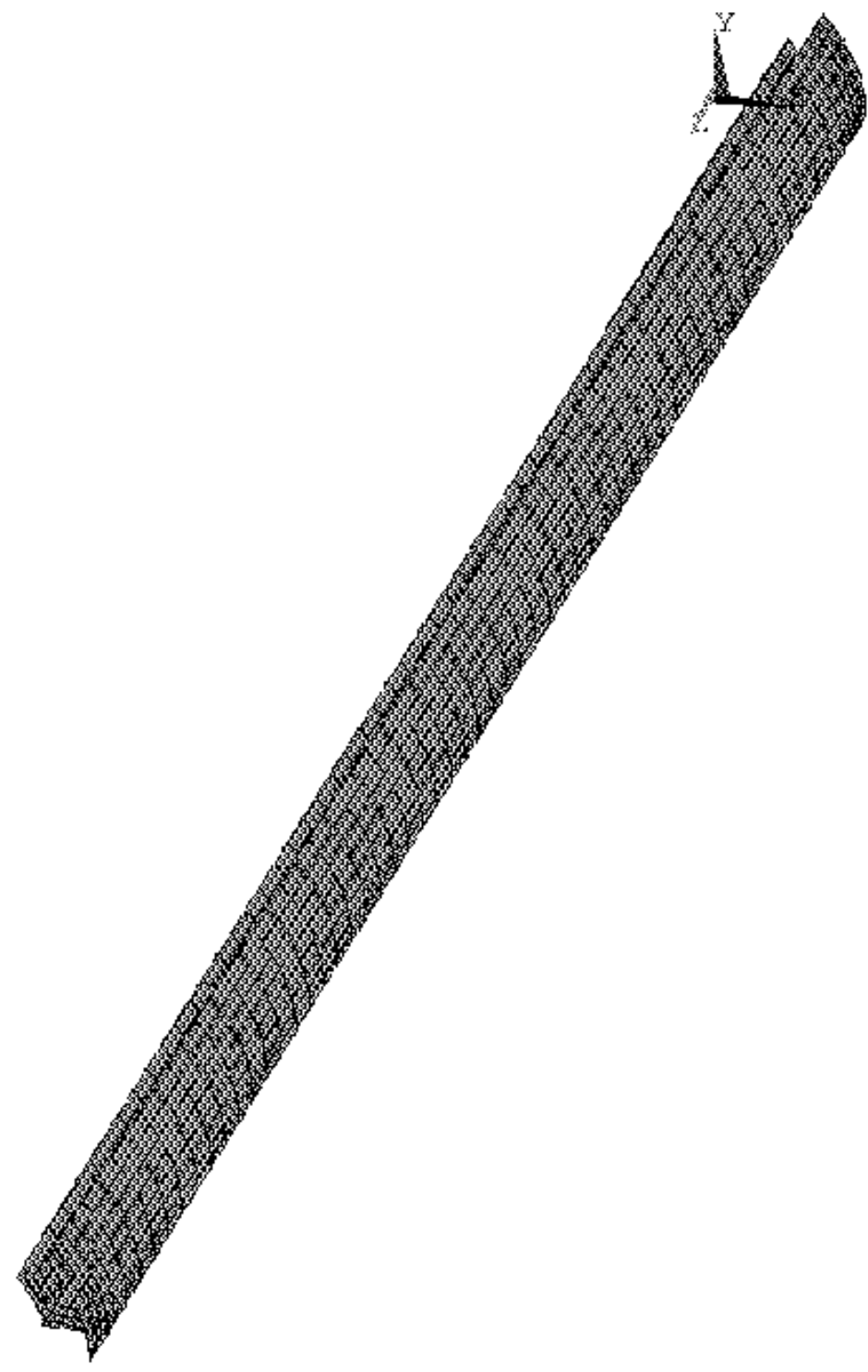

Figure 5. One-eighth symmetry finite element model of the CCL 


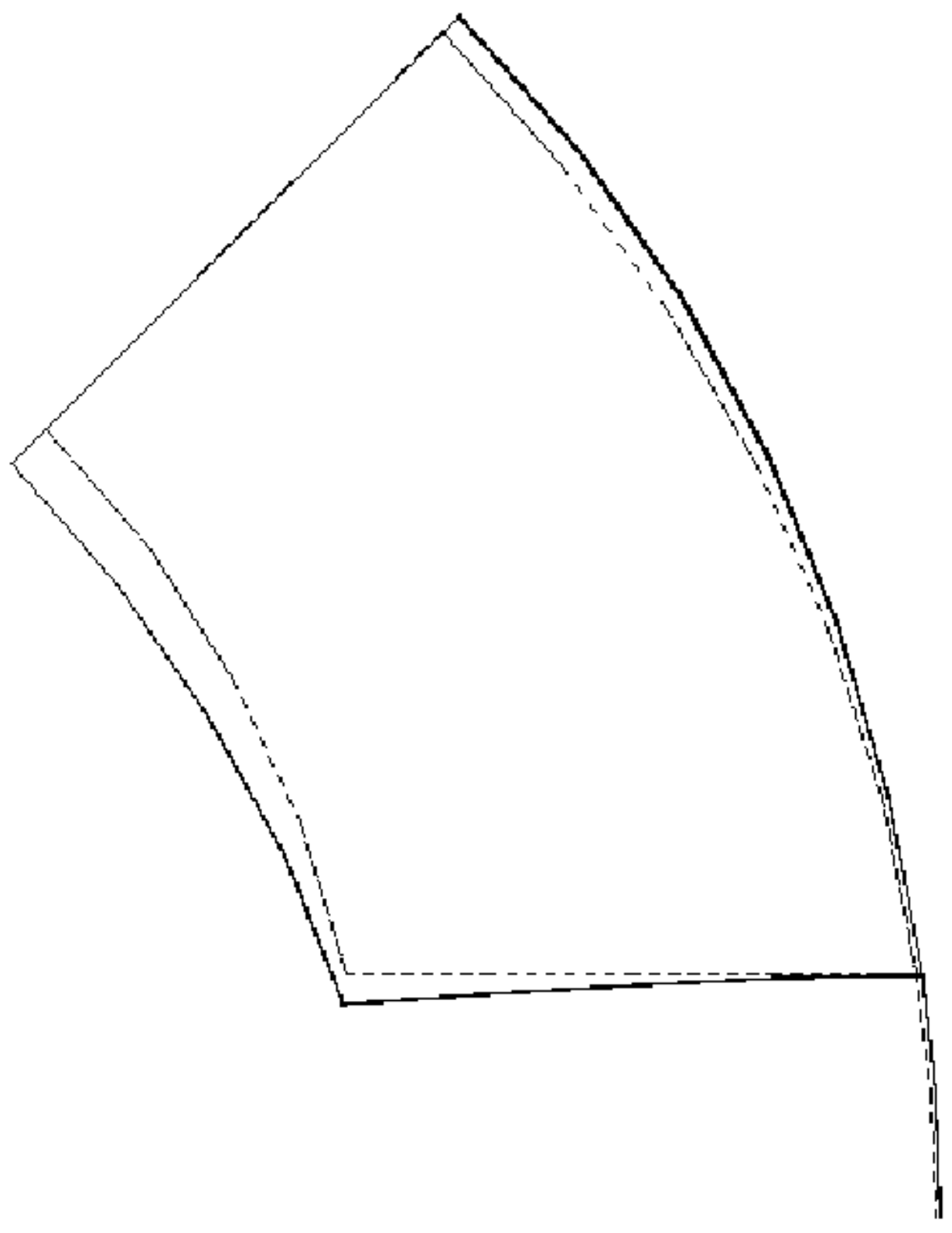

Figure 6a. Deformed cross-section shape at the axial position of maximum deformation: undeformed structure (dashed lines); deformed structure (solid lines) with webs present 


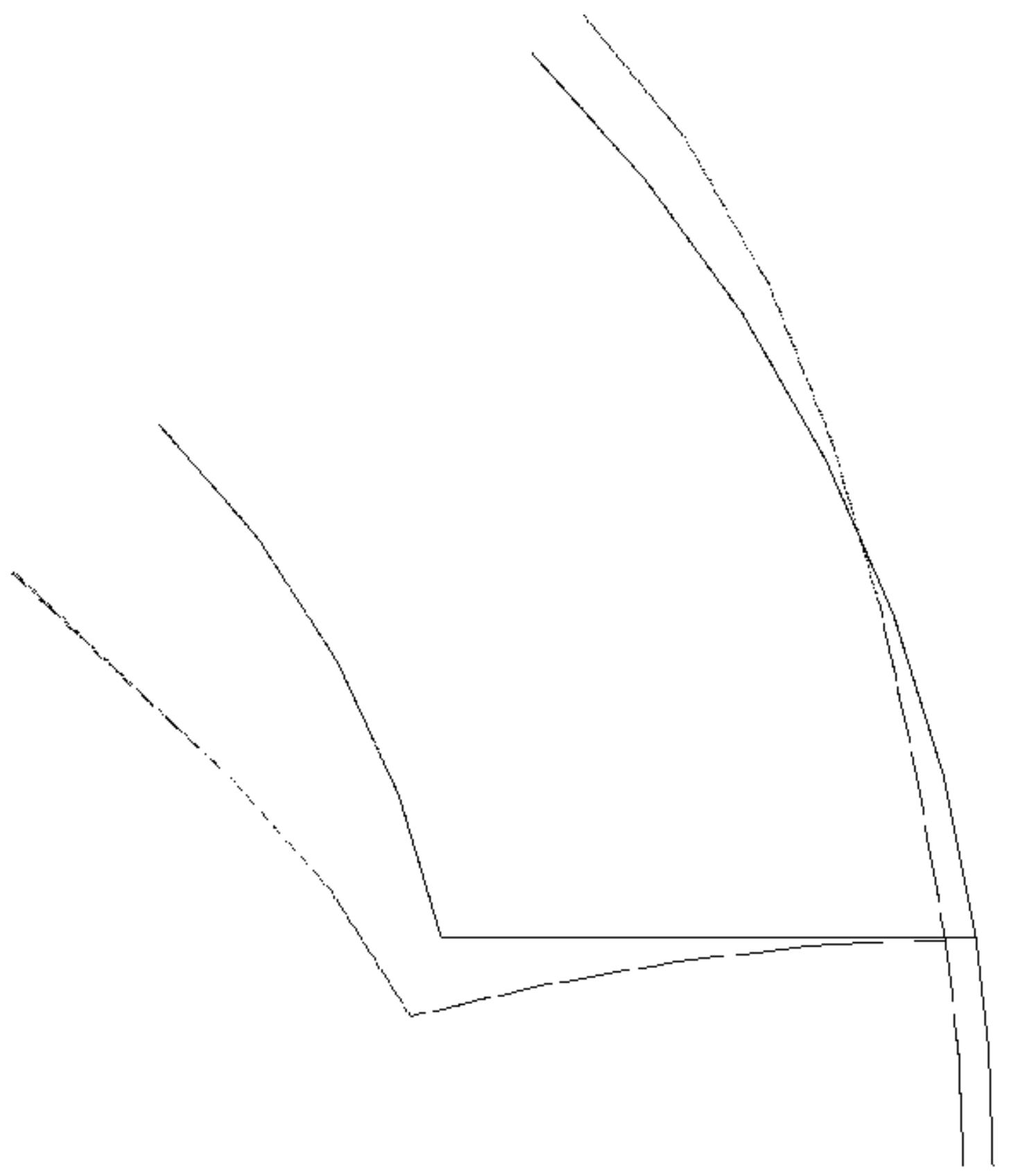

Figure 6b. Deformed cross-section shape at the axial position of maximum deformation: undeformed structure (dashed lines); deformed structure (solid lines) without webs present 


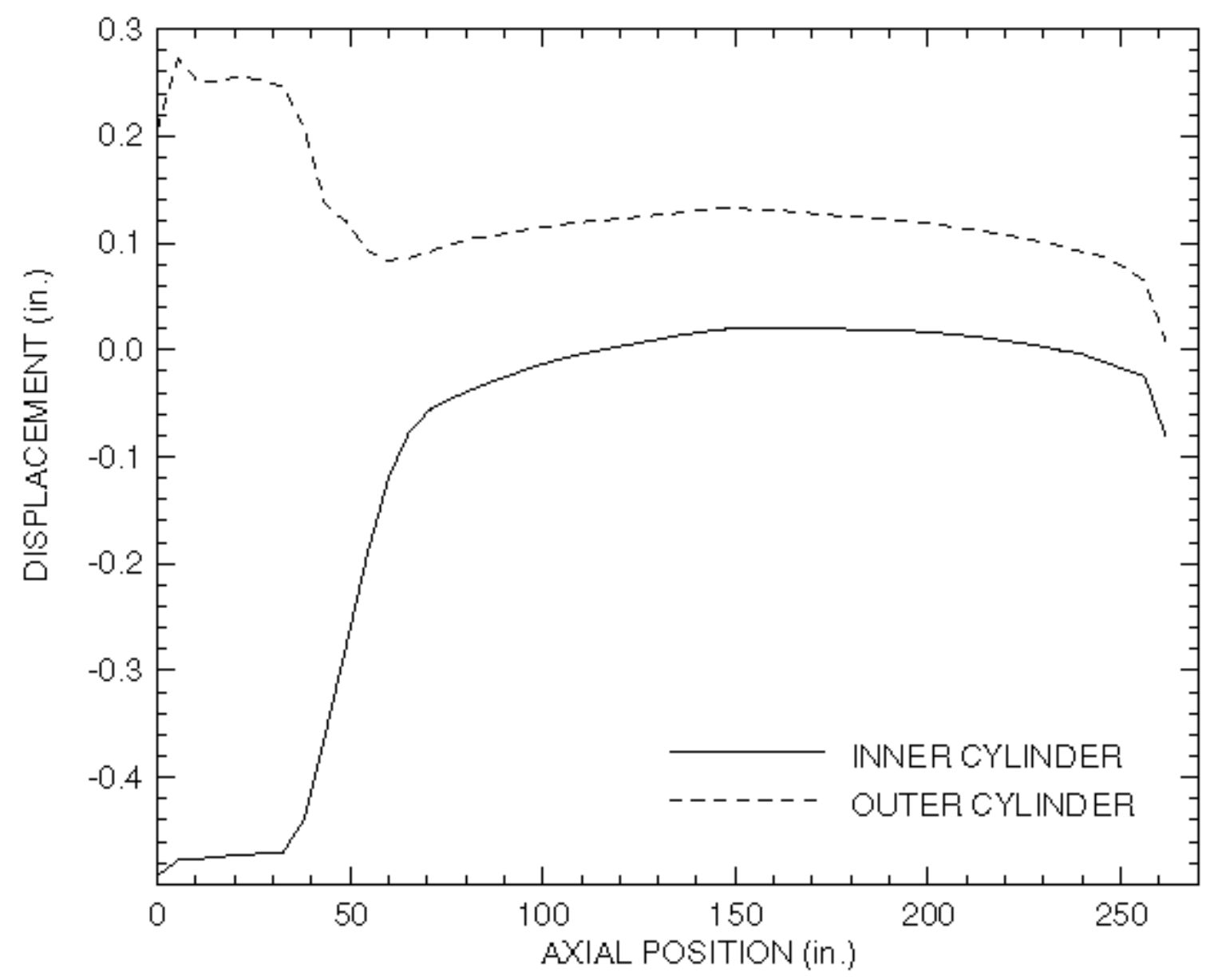

Figure 7a. Radial displacement at the center of the inner and outer cylinders as a function of axial position for load case 1 with webs present 


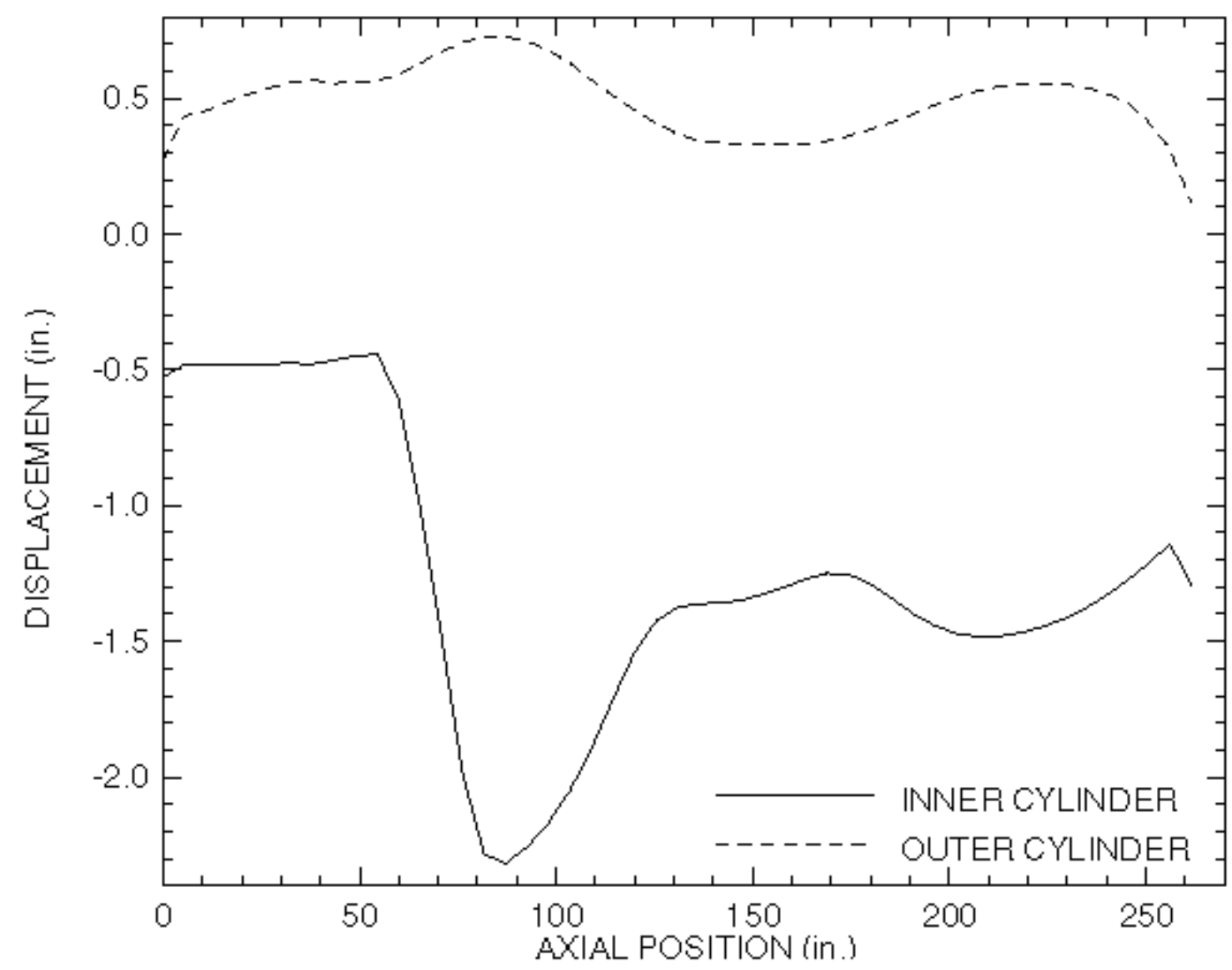

Figure 7b. Radial displacement at the center of the inner and outer cylinders as a function of axial position for load case 1 without webs present 


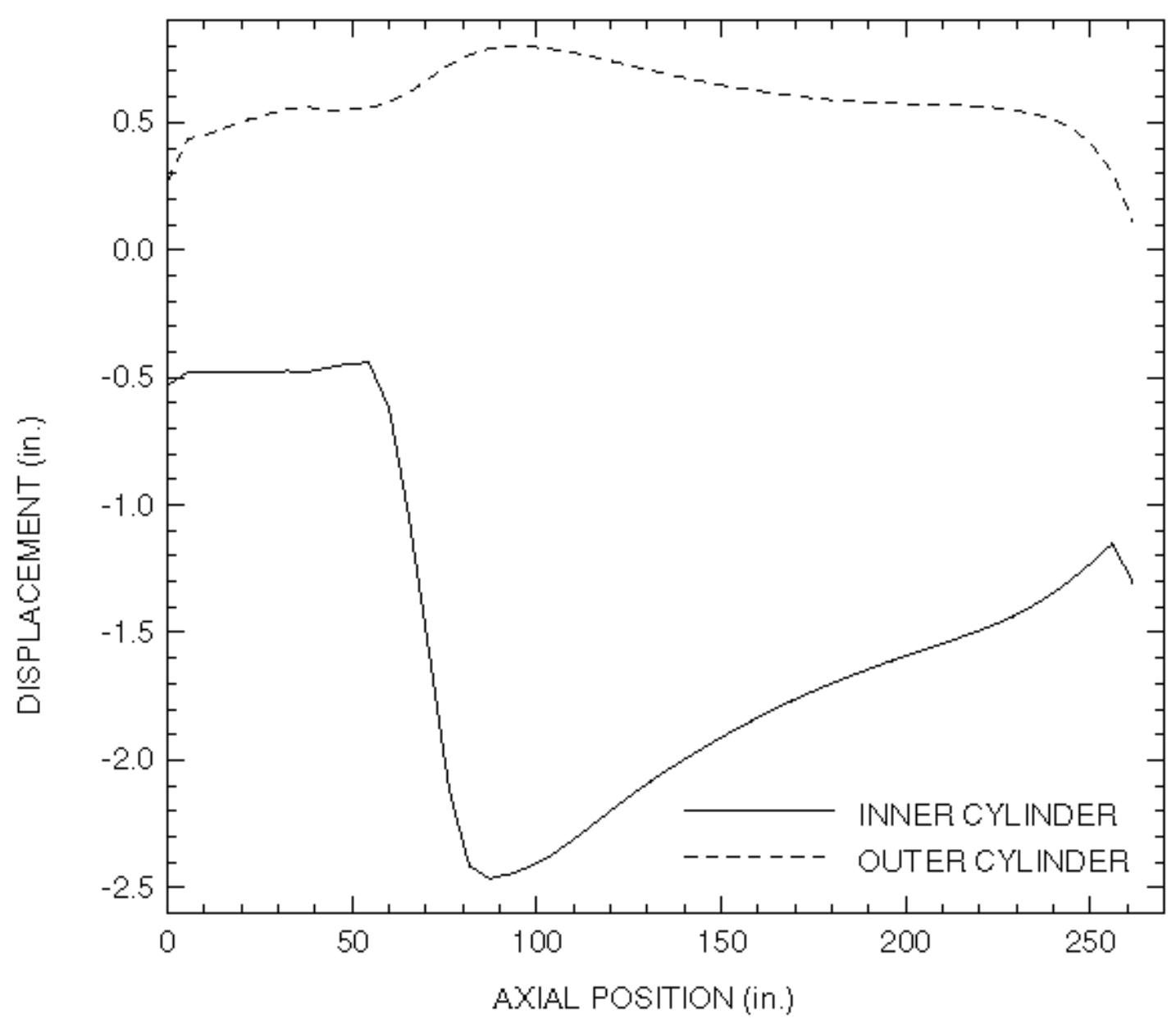

Figure 8. Radial displacement at the center of the inner and outer cylinders as a function of axial position for load case 2 (without missile fins or webs present) 


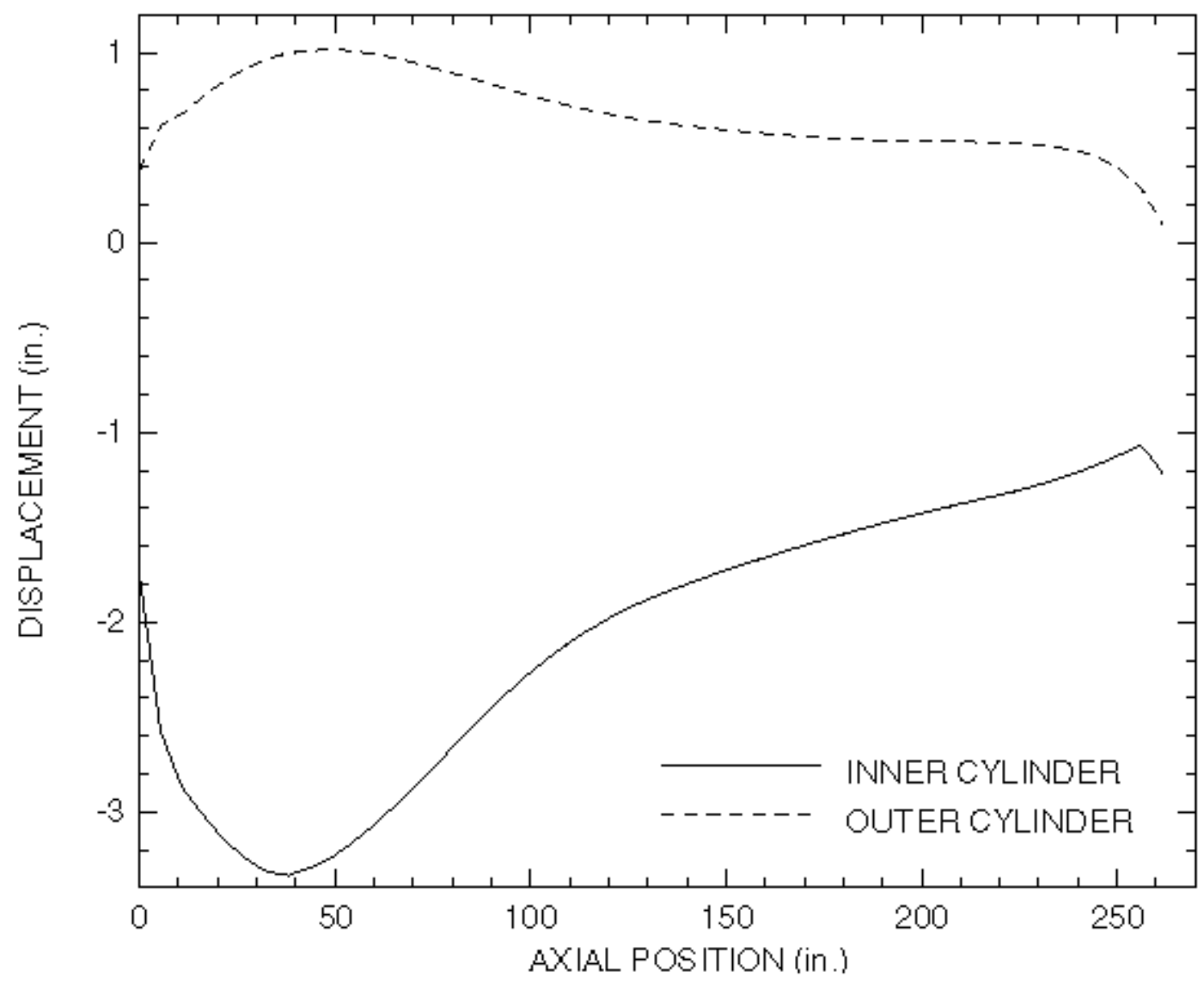

Figure 9. Radial displacement at the center of the inner and outer cylinders as a function of axial position for load case 3 (without rocket motor casing, missile fins, or webs present) 


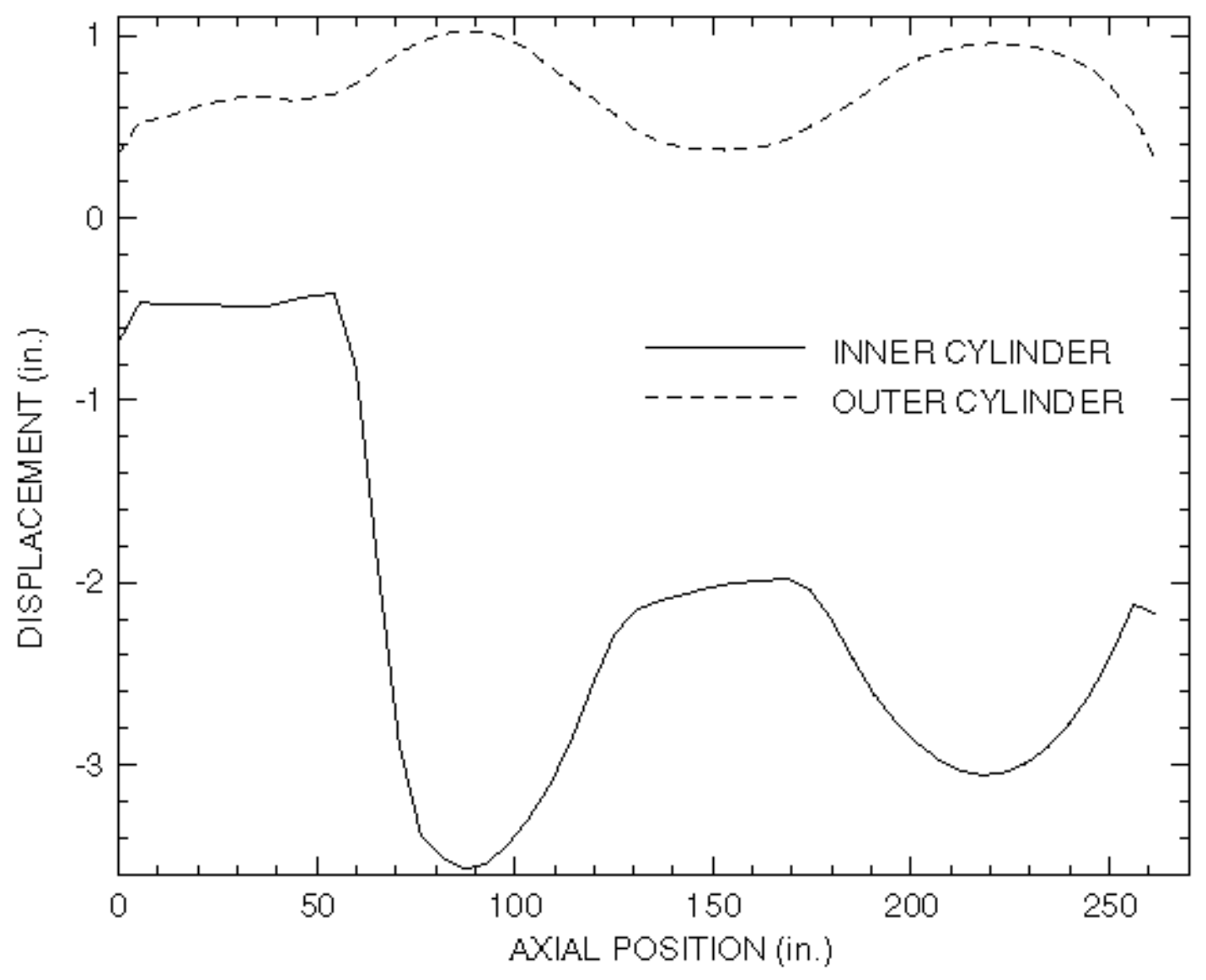

Figure 10. Radial displacement at the center of the inner and outer cylinders as a function of axial position for load case 1 (without webs present) subjected to over-pressurization 
APPENDIX A

TEMPERATURE DISTRIBUTIONS 


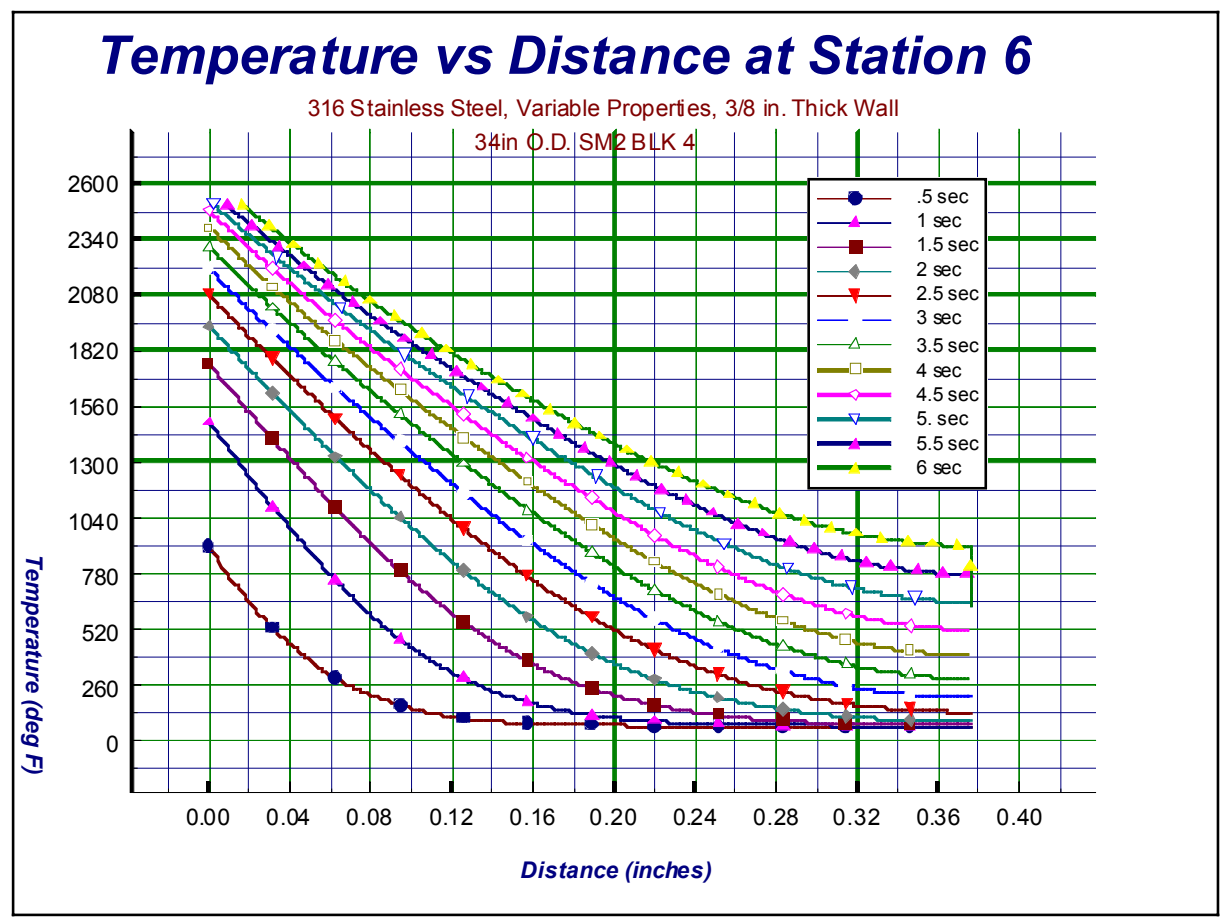

Figure A-1. CCL wall temperature as a function of time 6 inches from the base of the cylinder 


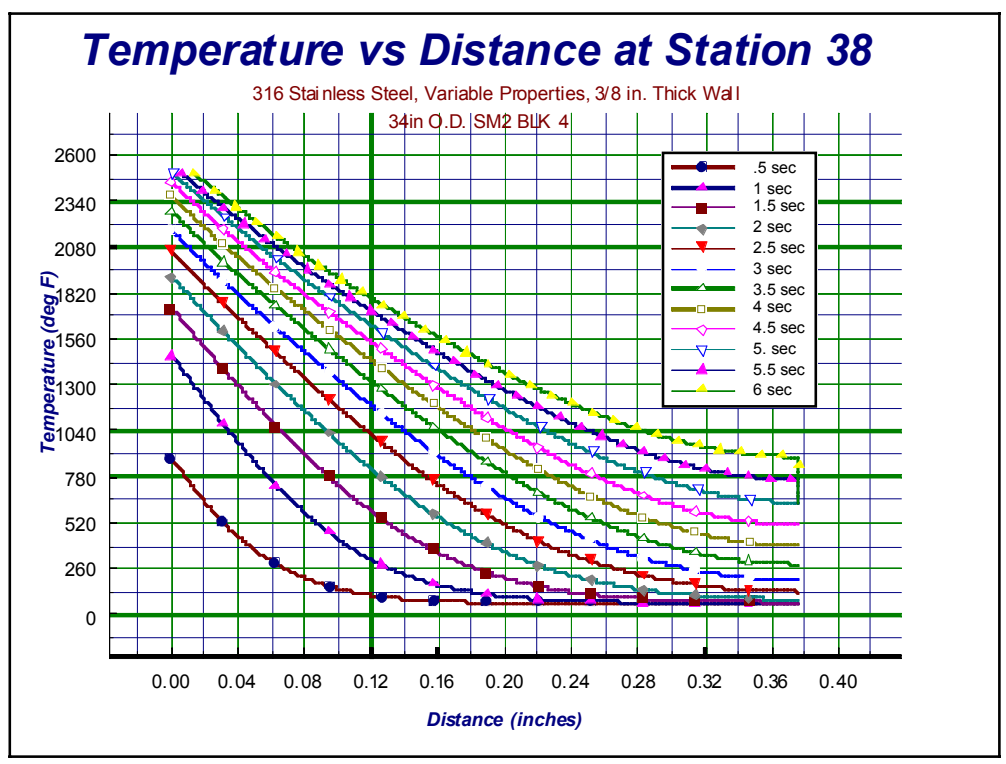

Figure A-2. CCL wall temperature as a function of time, 38 inches from the base of the cylinder 


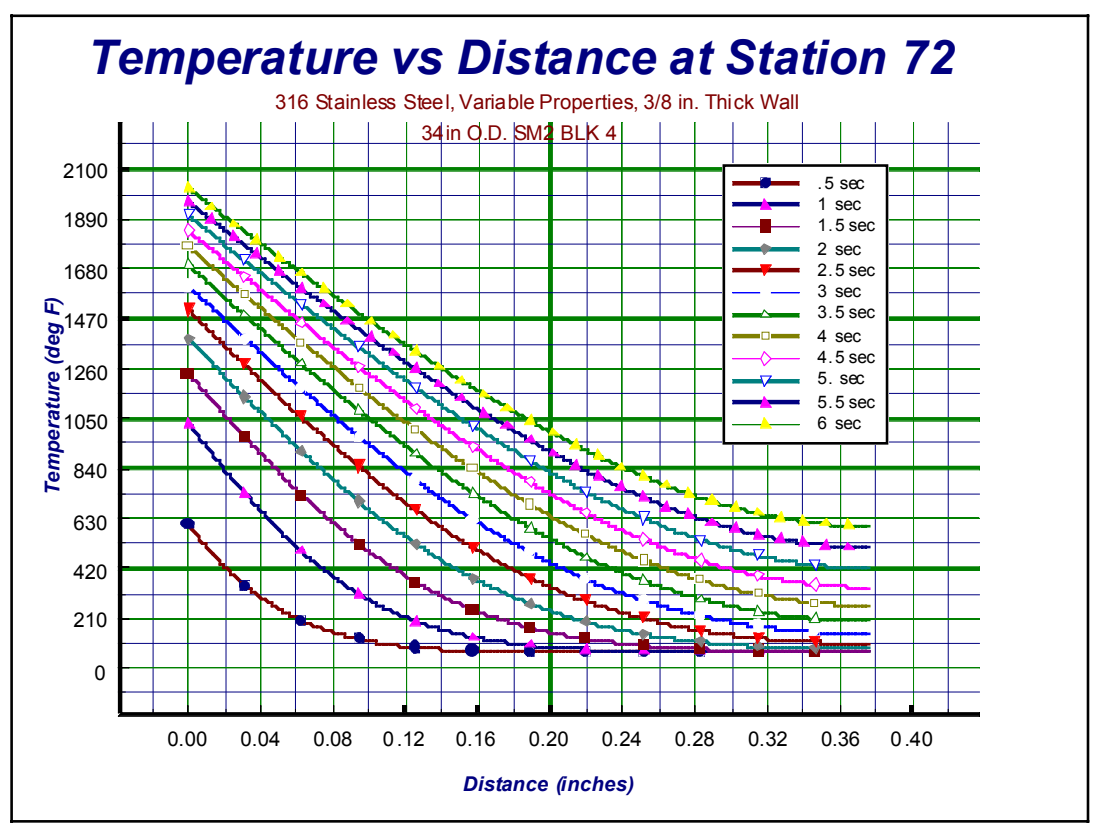

Figure A-3. CCL wall temperature as a function of time, 72 inches from the base of the cylinder 


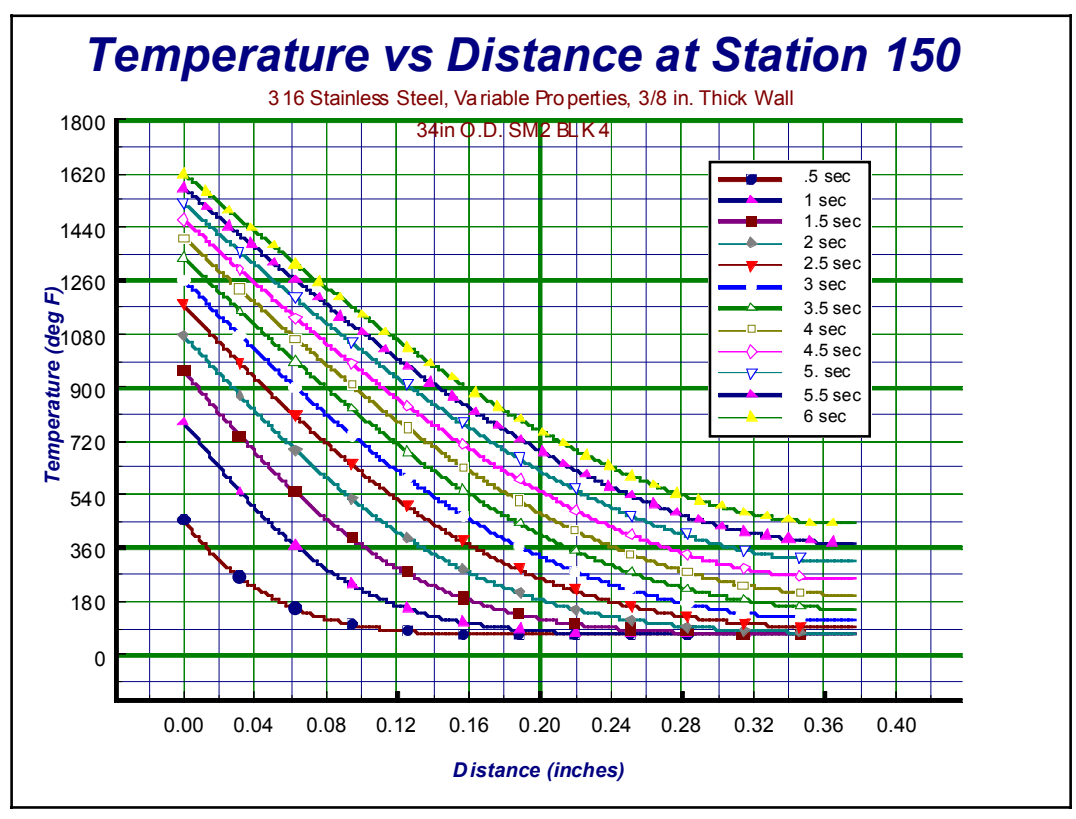

Figure A-4. CCL wall temperature as a function of time, 150 inches from the base of the cylinder 


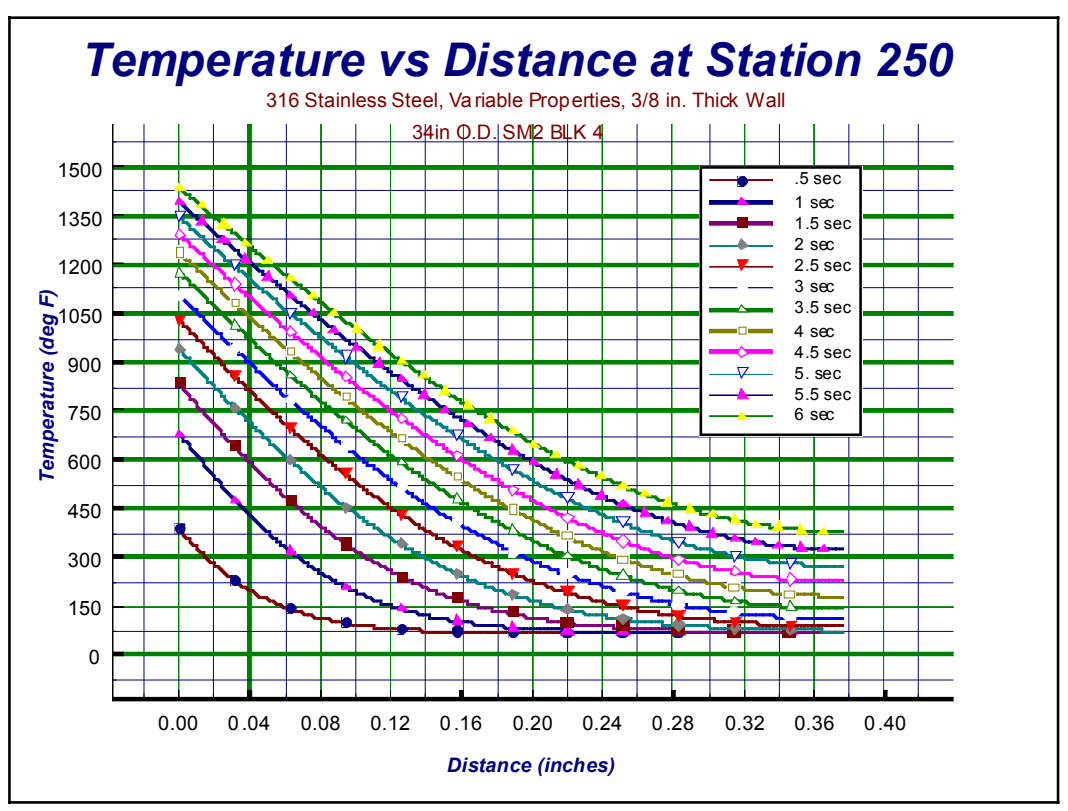

Figure A-5. CCL wall temperature as a function of time, 250 inches from the base of the cylinder 